Article

\title{
Application of Climate Based Daylight Modelling to the Refurbishment of a School Building in Sicily
}

\author{
Vincenzo Costanzo ${ }^{1, *(\mathbb{D})}$, Gianpiero Evola ${ }^{2}$ (D), Luigi Marletta ${ }^{2}$ and Fabiana Pistone Nascone ${ }^{2}$ \\ 1 School of the Built Environment, University of Reading, Whiteknights, Reading RG6 6AW, UK \\ 2 Department of Electric, Electronic and Computer Engineering, University of Catania, Viale A. Doria 6, \\ 95125 Catania, Italy; gevola@unict.it (G.E.); luigi.marletta@dii.unict.it (L.M.); \\ fabiana.pistonenascone@gmail.com (F.P.N.) \\ * Correspondence: v.costanzo@reading.ac.uk; Tel.: +44-1183-78-7379
}

Received: 29 June 2018; Accepted: 25 July 2018; Published: 28 July 2018

\begin{abstract}
This paper aims at promoting the use of Climate Based Daylight Modelling (CBDM) and related state-of-the-art metrics by discussing a range of design options to improve daylight fruition in rooms with different orientation, shape, function, and furniture of an elementary school that is located in the Mediterranean climate of Agira (Italy). The local climatic conditions, with clear skies for most of the year, require the integration of different shading and re-directing systems with the existing envelope and rooms' layout. Results show that the dynamic modelling is a powerful and 'creative' tool in the designer's hands, which helps to inform about the choice of the most appropriate technological solutions and on their architectural integration. Comparison with mostly used static daylight metrics, such as the average Daylight Factor $(a D F)$ and the Uniformity Ratio (UR), reveals a contrast with what would be suggested if considering these metrics alone, as prescribed by the Italian legislation. These outcomes rebate the need of performing more accurate and dynamic daylight simulations using recorded (i.e., varying) rather than fixed sky conditions to correctly inform the design process.
\end{abstract}

Keywords: daylighting; school building; measurement campaign; building simulation; climate based daylight modelling

\section{Introduction}

The concept of Climate-Based Daylight Modelling (CBDM) was introduced around 20 years ago by two seminal papers [1,2] that defined it as the prediction of any luminous quantity-mainly illuminance time series on a grid of ideal horizontal sensors-by considering the intrinsic variability of the sun and sky conditions as derived from standard weather data.

According to this approach, the use of hourly-or even finer-time steps to describe the relevant climate variables, as recorded by meteorological stations spread throughout the globe, allows for understanding the daylight distribution in a space under different climates and times of the year. This has the potential to revolutionize the way that daylight is conceived and assessed by practitioners and building scientists, while also questioning the reliability of the traditional approach that is based on the use of the Daylight Factor (DF) (or its spatial average $a D F[3]$ ), as prescribed by many regulatory bodies. It does not appear fortuitous then that very recently the Leadership in Energy and Environmental Design (LEED) rating system introduced the use of two dynamic metrics, such as the spatial Daylight Autonomy $(s D A)$ and the Annual Sunlight Exposure (ASE), for compliance purposes (Illuminating Engineering Society, LM-83 [4]), thus replacing the option of running simulations under fixed clear sky conditions. Furthermore, in 2013, the Education Funding Agency in the United Kingdom (UK) was the first public organization that made mandatory the use of the Useful Daylight Illuminance 
(UDI) metrics [5] for the evaluation of design proposals that were submitted to the Priority Schools Building Programme [6].

However, despite the indisputable advances achieved by considering real (i.e., recorded) time series of irradiance/illuminance values from largely available weather datasets, there are some concerns to bear in mind when adopting CBDM.

First, the choice of the weather dataset should be based on the purposes of the modelling and the underlying characteristics of the dataset itself (e.g., location, measurement period, statistical techniques being employed for resembling typical or extreme weather conditions). In fact, as demonstrated by Bellia et al. [7], using the IWEC (International Weather for Energy Calculation), Meteonorm, Satel-Light, or TRY weather sources could lead to different results in terms of Annual Light Exposures (i.e., the amount of light falling onto a certain point throughout the year, measured in luxh), and of various dynamic metrics, such as the Daylight Availability (DA, [8]) and the UDI. This happens because usually the TRY datasets show lower values for the global horizontal irradiance than in other sources; however, these outcomes were only proven for a north-oriented room, while different exposures could lead to different results because of sunlight contribution [7].

Secondly, there is a lack of consensus around the choice of the metrics and of their thresholds to judge if a space is 'well daylit' or not. The variety of CBDM approaches employed for educational buildings, ranging from traditional illuminance and luminance distribution under fixed sky conditions to novel circadian metrics, has been documented in a recent review paper by Costanzo et al. [9].

As an example, in regards to the above-mentioned adoption of the UDI metrics for school buildings design in the UK, Littlefair noted that the way calculations are conducted, in terms of offset distance from the walls, grid size, operational hours, and threshold values, might affect the outcomes [10]. This does not allow for comparison among spaces that are used for different purposes (e.g., schools, offices, houses).

Does it mean we should neglect the advances in daylight modelling, and stick to the current 50 years old practice? According to Tregenza [11], the daylight factor would still play a role in daylighting mandatory standards when a simple, robust, meaningful, and easy to test metrics is required for compliance with building codes, provided that a mandatory standard is the best option to achieve a good design. Nonetheless, the same author stated that CBDM should be used creatively, to explore new design solutions driven by different space requirements, orientations, and climate conditions.

Mardaljevic has critically assessed all of these aspects during a recent CIBSE technical symposium [12], demonstrating that, apart from a (quite) understandable 'shock of the new' for everyone that is involved in the fields of daylighting and lighting design, some of the critics are neither well-founded nor would automatically assign a preference to the old practice based on static illuminance ratios.

For example, the care in choosing the 'right' weather file is commonly accepted for thermal simulations, where, except for specific purposes, such as complying with energy performance certification requirements or peak loads calculations, steady-state methods are already put aside in favour of dynamic ones. It seems then that the daylighting simulation community is just a step away from doing it as well.

Furthermore, there is evidence of overheating and glare issues recorded in buildings designed to comply with the minimum $D F$ requirements, whose main rationale was to guarantee a minimum sufficient quantity of light for different visual tasks under the worst conditions of a standard overcast sky [13].

What appears more founded is rather the critique about the somehow subjective and arbitrary threshold values set for some of the CBDM metrics, such as $s D A, A S E$, and UDI (see the next section for their definition and calculation methods). In this sense, more case studies are needed to prove the concept and show their potentialities of informing on different design solutions when being 'creatively' used. 
This paper contributes to advance the familiarity with the use of dynamic daylight simulations by presenting a range of design options fitting the needs of different users of a surveyed elementary school that is located in the Mediterranean climate of Agira (Sicily). The local climatic conditions, mostly sunny throughout the year, indeed require the integration of different shading and re-directing systems with the existing envelope and rooms' layout, a task that has been accomplished by employing several CBDM and static metrics. Results show that the dynamic modelling of the spaces is a powerful tool in the designer's hands, helping to inform about the choice of the most appropriate technological solutions and their architectural integration.

\section{Methodology}

In order to perform an accurate daylight analysis, in Section 2.1, state-of-the-art metrics are presented and commented to show their peculiarities and provide a rationale for their use. Then, in Section 2.2, the building and the experimental campaign are described; finally, the development of a model that is used for running daylight simulations is described in Section 2.3. The simulations were run for both the current configuration of the building and for a series of proposed interventions that are aimed to improve daylight fruition.

\subsection{Static and Dynamic Metrics: Which Ones do Fit the Purpose?}

As introduced in Section 1 and reported in ref. [9], a number of static and dynamic metrics have been employed in previous studies concerning daylight in schools. In this research, we chose to use both traditional 'static' and more recent 'dynamic' metrics to highlight the differences in terms of applicability and derived outcomes. Furthermore, standard metrics, such as the average Daylight Factor $(a D F)$ and the Uniformity Ratio $(U R)$ have been considered to inform about daylight distribution under the worst-case condition of an overcast sky. These static metrics are also prescribed by Italian regulations, which set the achievement of minimum thresholds for compliance purposes. The mathematical formulation for these metrics is reported in Equations (1)-(3):

$$
\begin{gathered}
D F=\frac{E_{i}}{E_{o}} \\
a D F=\frac{T \cdot W \cdot \theta \cdot M}{A \cdot\left(1-R^{2}\right)} \\
U R=\frac{E_{\min }}{E_{a v g}}
\end{gathered}
$$

The first equation represents the classical definition of punctual Daylight Factor, expressed as the percent ratio of the indoor illuminance value $E_{i}$ to the outdoor horizontal illuminance value $E_{o}$ under a standard CIE overcast sky luminance distribution. The second equation expresses the spatial average $D F$, according to the simplified formulation proposed by Crisp and Littlefair [3] for a room of total enclosing surface area $A$ (opaque and transparent), showing an average reflectance $R$ and equipped with windows of effective transmittance $T$ and area $W$. In Equation 2, $\theta$ is the angle subtended by the visible sky from the centre of a window in a vertical plane and $M$ is the maintenance factor.

The Uniformity Ratio (UR) is instead defined as the ratio of the indoor minimum illuminance value $E_{\min }$ to the average value $E_{a v g}$, under the same overcast sky conditions that are used for the $D F$ calculations.

The CBDM metrics adopted are the Useful Daylight Illuminance (UDI), the spatial Daylight Autonomy $(s D A)$, and the Annual Sunlight Exposure $(A S E)$, all of which are defined with reference to an ideal horizontal grid of sensor points. The rationale behind their selection is that all of them are complimentary to each other and help in depicting both the temporal and spatial distribution of daylight in a comprehensive way. In fact, the UDI metrics informs about the percent of occupied hours in which the illuminance value in a specific point of the room falls within a specific illuminance bin; 
in many cases, the UDI is also determined in relation to the spatial mean illuminance value. In this study, three different bins are considered for the illuminance: lower than 100 lux (insufficient daylight), between 100 and 2000 lux (appropriate daylight) and higher than 2000 lux (potential glare), as suggested in the original formulation of Nabil and Mardaljevic [5]. It is worth mentioning that a later study suggested increasing the upper threshold to 3000 lux [14]. On the other hand, the $s D A$ metrics informs on the percentage of space achieving a target illuminance value for a specified amount of time in a year. According to the definitions that are given in the IES-LM-83-12 Standard [4], the target illuminance value for $s D A$ is 300 lux and the amount of time above which this value should be retained is $50 \%$ of the occupied hours.

Finally, the ASE metrics expresses the percentage of space for which direct sunlight only (i.e., without considering any internal and exterior reflections and blinds operation) exceeds a threshold value for a fixed number of hours. The illuminance threshold is set to 1000 lux, while the number of annual hours exceeding this value should be lower than 250, otherwise discomfort glare may occur.

The mathematical formulation adopted for these metrics in this paper is reported in Equations (4) and (5):

$$
\begin{gathered}
U D I=\frac{\sum_{i=1}^{n} t_{i} x_{i}}{\sum_{i=1}^{n} t_{i}} \quad \text { with } x_{i}=\left\{\begin{array}{l}
1 \text { if } E_{\text {avg }} \text { is within the bin } \\
0 \text { if } E_{\text {avg }} \text { is outside the bin }
\end{array}\right. \\
s D A=\frac{\sum_{i=1}^{n} \sum_{j=1}^{p} x_{i, j}}{\sum_{j=1}^{p} p_{j} \cdot \sum_{i=1}^{n} t_{i}} \quad \text { with } x_{i, j}=\left\{\begin{array}{l}
1 \text { if } E_{i, j} \geq E_{\text {threshold }} \\
0 \text { if } E_{i, j}<E_{\text {threshold }}
\end{array}\right.
\end{gathered}
$$

In Equation (4), the spatial average of the illuminance values is considered; here, $t_{i}$ is the $i$-th occupied hour and $x_{i}$ is a binary function that, according to the mean illuminance recorded in the $i$-th occupied hour, is $x_{i}=1$ if this falls within the bin and $x_{i}=0$ otherwise. In Equation 5, $p_{j}$ is the generic $j$-th sensor node on the horizontal calculation grid, while the binary function becomes $x_{i j}$ to account for a double summation over both the temporal and spatial domains being this metrics defined as a spatial average. The expression for the ASE metrics is the same as for the $s D A$ metrics, with differences in the calculation method (i.e., only the direct sunlight contribution is considered for illuminance appraisal) and thresholds (see Table 1).

Finally, the risk of glare occurrence can be studied for some points of view by calculating the Daylight Glare Probability (DGP) index, which, according to Carlucci et al. and Pierson et al. $[15,16]$, is one of the most robust approaches for glare assessment. In fact, it is able to account for both the saturation effect when the amount of light reaching the eye is too large, and the contrast effect when the contrast between the visual task and the field of view is too strong. These two aspects are considered in the vertical illuminance at eye level $E_{v}$ and in the logarithmic term of Equation (6):

$$
D G P=5.87 \cdot 10^{-5} E_{\mathcal{v}}+0.0918 \cdot \log \left[1+\sum_{i=1}^{n}\left(\frac{L_{s, i}^{2} \cdot \omega_{s, i}}{E_{v}^{1.87} \cdot P_{i}^{2}}\right)\right]+0.16
$$

Here, $L_{s}$ is the luminance of the $i$-th glare source, $\omega_{s}$ is the solid angle through which the glare source is seen, and $P_{i}$ is the position index. It is important to note that, unlike the other metrics, the DGP reports the probability that a person is disturbed by glare in a scale of $20 \%$ to $80 \%$ [17], rather than a percent of time or space achieving a target value (see Table 1).

Because of current computational limitations, most of the available daylight simulation tools make use of a simplified version of the DGP, defined by Wienold in $[18,19]$ and known as DGPs:

$$
D G P s=6.22 \cdot 10^{-5} E_{v}+0.184
$$


Table 1. Thresholds and target values of the metrics employed *.

\begin{tabular}{|c|c|c|c|}
\hline Metrics & Space and Time Domain & Target/suggested Value & Source \\
\hline$a D F$ & $\begin{array}{l}\text { Space average over a grid of points, } \\
\text { Fixed sky luminance conditions }\end{array}$ & $\begin{array}{l}>3 \% \text { for classrooms } \\
>2 \% \text { for other rooms }\end{array}$ & {$[20,21]$} \\
\hline UR & $\begin{array}{l}\text { Space average over a grid of points, } \\
\text { Fixed sky luminance conditions }\end{array}$ & $\begin{array}{l}>60 \% \text { for classrooms } \\
\text { Not specified for other rooms }\end{array}$ & {$[20,21]$} \\
\hline UDI & $\begin{array}{l}\text { Punctual or space average over a grid of } \\
\text { points, Hourly sky luminance conditions }\end{array}$ & Not specified & [5] \\
\hline$s D A$ & $\begin{array}{l}\text { Space average over a grid of points, } \\
\text { Hourly sky luminance conditions }\end{array}$ & $\begin{array}{l}>55 \% \text { for acceptance } \\
>75 \% \text { for preference }\end{array}$ & [4] \\
\hline$A S E$ & $\begin{array}{l}\text { Space average over a grid of points, } \\
\text { Hourly sky luminance conditions }\end{array}$ & $\begin{array}{l}<10 \% \text { for acceptance } \\
<7 \% \text { for neutrality } \\
<3 \% \text { for preference }\end{array}$ & [4] \\
\hline$D G P s$ & $\begin{array}{l}\text { Observer's viewpoint dependent, } \\
\text { Hourly sky luminance conditions }\end{array}$ & $\begin{array}{c}<0.35 \text { imperceptible glare } \\
0.35-0.40 \text { perceptible glare } \\
0.40-0.45 \text { disturbing glare } \\
>0.45 \text { intolerable glare }\end{array}$ & [18] \\
\hline
\end{tabular}

Here, the influence of the single glare sources is neglected, an assumption that proved to provide reliable results in the absence of direct sunlight transmission and peak reflections through the façade in the observer's direction [19]. Within these validity constraints, four different bands are suggested for categorization purposes: imperceptible glare $(D G P s<0.35)$, perceptible glare $(0.35 \leq D G P s<0.4)$, disturbing glare $\left(0.4 \leq D G P_{S}<0.45\right)$, and intolerable glare $(D G P S \geq 0.45)$ [18]. In this way, numerical outcomes can directly be used as for the other metrics, since they do not refer any more to a probability distribution. For all these reasons, DGPs is used as a glare metrics in this study.

\subsection{Case Study Building and the Experimental Campaign}

The case study building is an elementary school located in Agira (Italy), a town that is characterized by the warm and sunny climate conditions of a typical Mediterranean island like Sicily. The building shows an E shape with the main façade and the two lateral wings hosting about 30 classrooms on two floors (rooms' height of $4.50 \mathrm{~m}$, total floor area of around $4600 \mathrm{~m}^{2}$ ), while the central wing is separated from the lateral ones by means of two courtyards and hosts the gym (see Figure 1). A long corridor running along the north side gives access to the different rooms, all of which are side lit by two or more double-glazed PVC windows that are equipped with external plastic roller shades. This configuration is different for the gym, which has windows placed on all three external walls and has no shading provision.

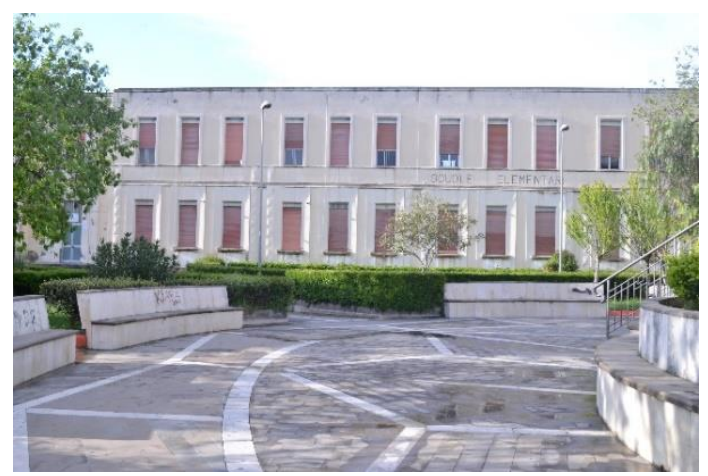

(a)

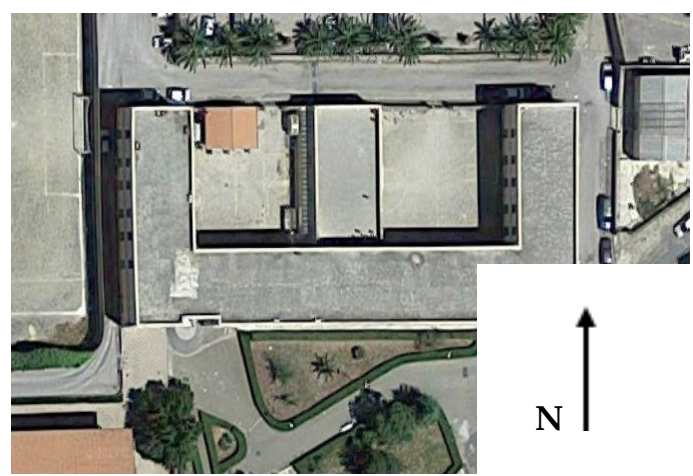

(b)

Figure 1. Guglielmo Marconi elementary school in Agira. (a) External view of the main facade; and, (b) Aerial view. 
For the sake of assessing the daylight availability inside the school, three rooms with different functions, orientations, and features have been surveyed: a typical classroom and a computer classroom facing south, and the gym with openings to the north, west, and east oriented facades (see Figure 2).

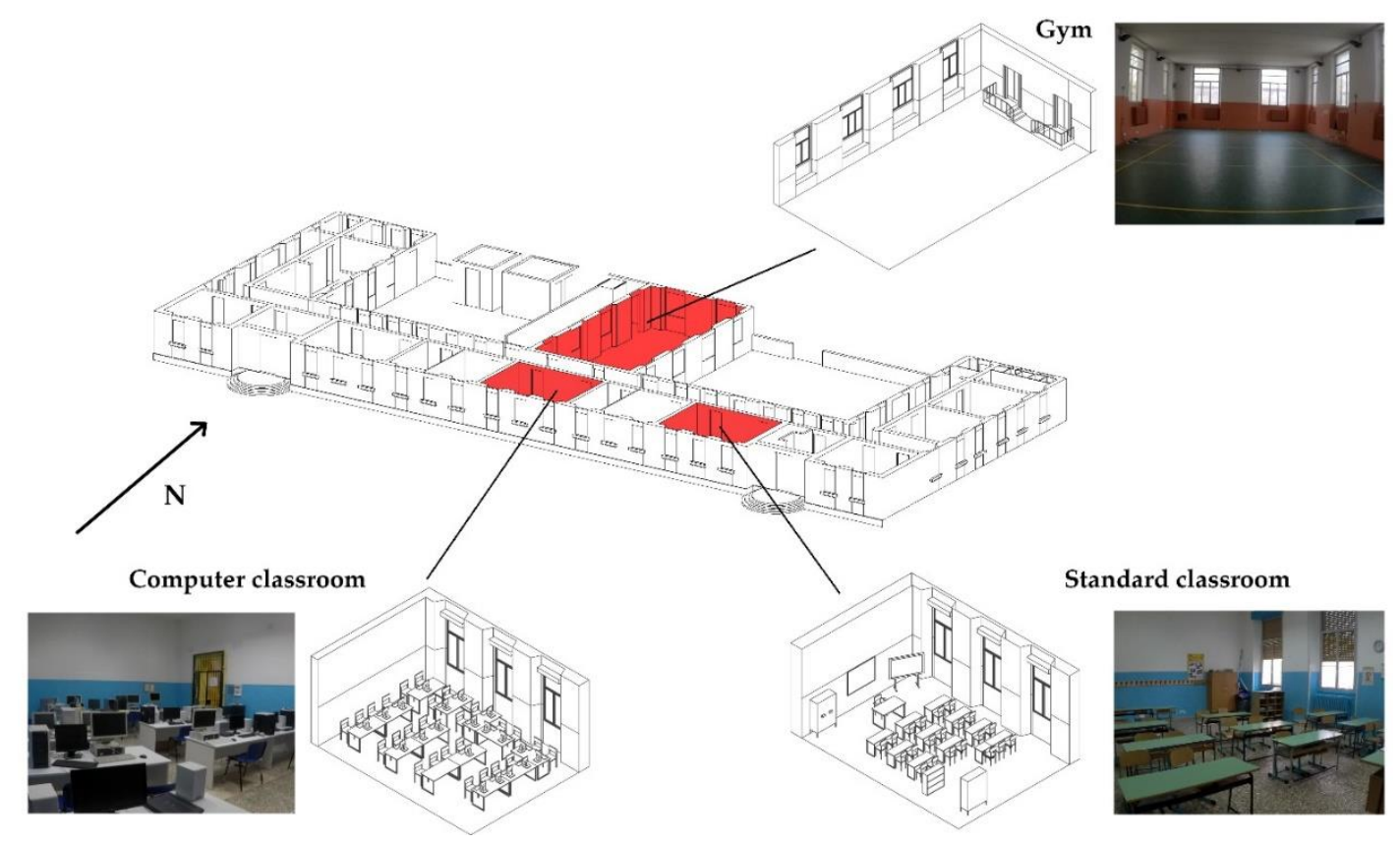

Figure 2. Axonometric views and pictures of the study rooms.

Unfortunately, by the time that the measurement campaign was carried out, the rooms on the west and east wings were not accessible. However, most of them are used for office purposes and not for teaching and learning activities.

Concerning the features of the selected rooms, the standard and computer classrooms have the same size $\left(8.8 \times 6.1 \times 4.5 \mathrm{~m}^{3}\right)$, three openable windows of $1.6 \mathrm{~m}^{2}$ size each exposed due to south, placed at $1.2 \mathrm{~m}$ from the floor, and equipped with a $0.9 \mathrm{~m}^{2}$ wide clerestory. The interior finishing layer of the walls and the ceiling is of cement plaster painted with a white colour, except for a light blue belt at $2 \mathrm{~m}$ from the floor, while the floor itself is made up of granite tiles. In order to keep a high level of detail for modelling, the existing furniture has been considered as well. The standard classroom is furnished with a traditional blackboard and an interactive whiteboard on one of the shortest sides of the room, a closet on the opposite side and a number of desks to accommodate the pupils and the teacher (see Figure 2). The computer classroom instead presents a series of desks with 25 LCD screens and cases.

The gym shows an open plan layout $\left(18.5 \times 9.8 \times 4.5 \mathrm{~m}^{3}\right)$, the walls and the ceiling have the same interior finishing layer of the standard and computer classrooms painted white but with a light pink coloured belt of $2 \mathrm{~m}$ height from the floor, which is finished with an anti-slip green coloured PVC layer. Ten windows (four on each of the long sides, two on the north oriented wall) that are placed at $2 \mathrm{~m}$ from the floor and equipped with a clerestory (for a resulting window area of $4.8 \mathrm{~m}^{2}$ ) bring daylight inside.

The visible reflectance of all indoor opaque surfaces has been calculated through Equation (8), under the hypothesis that the opaque finishing layers behave as a Lambertian diffuser (i.e., equal reflectance for all directions). The luminance $L$ to be used in Equation (8) is the mean value from three spot luminance measurements, which are gathered through a MINOLTA LS 100 luminance meter (measurement range $0.01-50 \mathrm{kcdm}^{-2}$, accuracy $\pm 0.2 \%$ ). Similarly, the average of three illuminance measurements, collected through a MINOLTA T-10A lux meter (measurement range 0.01-300 klux, accuracy $\pm 3 \%$ ), allows for assessing the illuminance value $E$ in Equation (8). 
The visible transmittance of the glazing is calculated at the center of the glass as the ratio of the recorded indoor vertical illuminance close to the windows (measured with the lux meter facing the glazing) to the outdoor vertical illuminance measured just outside the window with the lux meter facing outdoor, see Equation (9). The indoor and outdoor illuminance measurements have been taken simultaneously using tripods on 26 February under partly overcast sky conditions. The resulting values, which are used as an input to the software, are listed in Table 2.

$$
\begin{gathered}
\rho=\frac{\pi L}{E} \\
\tau=\frac{E_{\text {indoor }}}{E_{\text {outdoor }}}
\end{gathered}
$$

Table 2. Optical properties of the surfaces in the selected rooms.

\begin{tabular}{cc}
\hline Material & Reflectance/Transmittance \\
White walls & 0.78 \\
Blue belt (walls) & 0.35 \\
Pink belt (walls) & 0.38 \\
Granite tiles & 0.31 \\
Green PVC layer & 0.12 \\
White ceiling & 0.82 \\
Desks finishing (green) & 0.37 \\
Blackboard & 0.13 \\
Interactive whiteboard & 0.80 \\
Wooden chairs & 0.35 \\
Blue plastic chairs & 0.15 \\
Wooden closet & 0.26 \\
Steel frames (desks and chairs) & 0.21 \\
PVC windows frames & 0.48 \\
PC screens & 0.14 \\
Computer and classrooms windows* & 0.74 \\
Gym windows* & 0.65 \\
\hline * &
\end{tabular}

\subsection{Daylighting Simulations and Calibration of the Model}

The appraisal of daylight conditions has been conducted by means of dynamic simulations in DIVA [22], a tool that makes use of the well-validated backward ray-tracing method that was provided by Radiance [23]. Given the similarities between the standard classroom and the computer room, the calibration of the model has been carried out only for the standard classroom and the gym, by fine-tuning the more relevant radiance parameters, namely ambient bounces $-\mathrm{ab}$, ambient accuracy-aa, ambient sample-as, ambient divisions-ad, and ambient resolution-ar. The reader can get a thorough understanding of these and other Radiance parameters by consulting [24].

The rooms are supposed to be occupied all year long from 8AM to 1PM on Monday to Friday, except from half of June to half of September (summer break) and for some weeks during the winter break, for a total of 1122 hours per year.

The grid of sensor points has been placed on an ideal 'work plane' identified at desks height in the standard and computer classrooms and at $1 \mathrm{~m}$ from the floor in the gym. In both cases, the grid has an offset of $0.5 \mathrm{~m}$ from the walls, as suggested by the Italian legislation [20], which also prescribes the use of a calculation grid whose maximum spacing $p$ is defined as a function of the maximum room size $d$ through Equation (10):

$$
p=0.2 \cdot 5^{\log d}
$$

This computation results in a square grid of $0.8 \mathrm{~m}$ spacing in the case of the standard and computer classrooms, and of $1.8 \mathrm{~m}$ spacing in the gym.

For the sake of brevity, the results of the model calibration are presented in Figure 3 for the standard classroom only in the form of gradient contour lines, where the measured illuminance values 
((a) panel) are compared to those that are resulting from the simulations ((b) panel). From this picture, it is easy to appreciate how well the simulated illuminance values follow the measured values in terms of both magnitude (illuminance differences are always lower than $12 \%$ ) and spatial distribution. In both cases, the half of the classroom that is farther from the windows keeps below 500 lux, while in the other half, the illuminance values frequently keep between 500 lux and 1000 lux. The main differences are detected close to the windows, where the effects of direct sunlight is more evident in the measurements. As an example, the measurements pointed out a spot of direct sunlight close to the middle window that is not detected by the simulations. The main reason for this discrepancy is the approximation of climate conditions due to the lack of weather time series for the town of Agira (LAT. $37^{\circ} 39^{\prime} \mathrm{N}$, LON. $14^{\circ} 31^{\prime} \mathrm{E}$, altitude of $824 \mathrm{~m}$ above the sea level). Indeed, the closest weather dataset available, provided in the Typical Meteorological Year format (TMY, [25]) and used in this research, is that pertaining to the city of Catania (LAT. $37^{\circ} 30^{\prime} \mathrm{N}, \mathrm{LON} .15^{\circ} 05^{\prime} \mathrm{E}$, altitude of $7 \mathrm{~m}$ above the sea level).

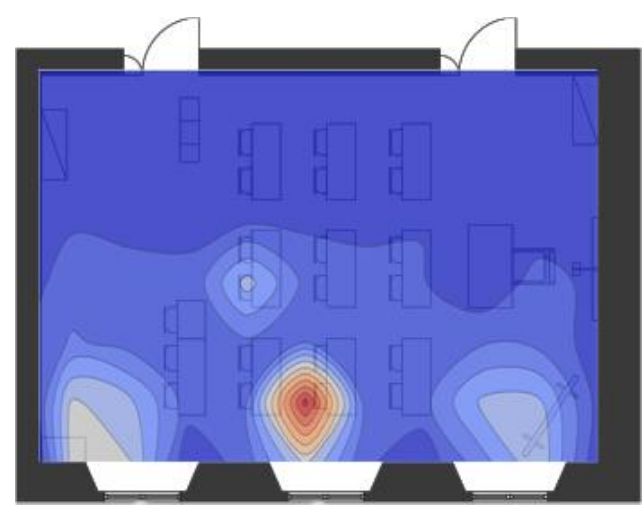

(a)

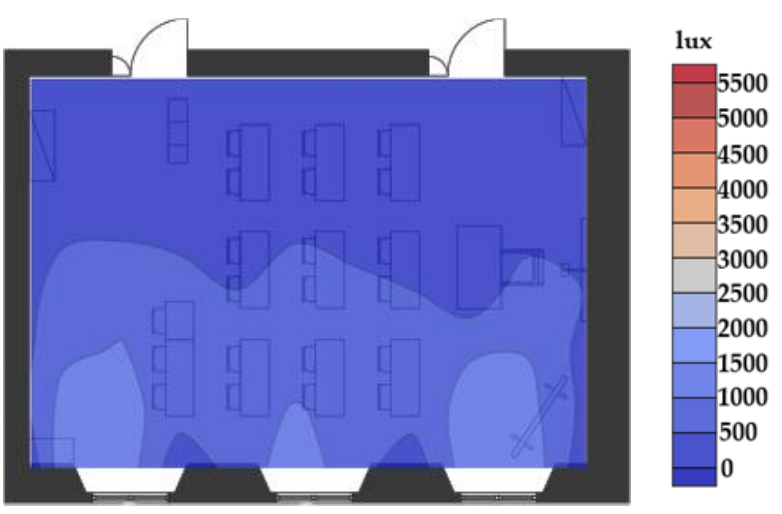

(b)

Figure 3. Comparison between measured (a) and simulated (b) illuminance levels for the standard classroom on 26 February at 11:30 a.m.

Notwithstanding this limitation, similar results are obtained for the gym (a maximum punctual difference of around $23 \%$ is reached for the points furthest away from the windows) and the model can be considered to be calibrated. The resulting Radiance parameters are listed in Table 3. Here, it is worth to discuss how the coarser values that are chosen for the gym derive mainly from its geometry and the absence of any furniture to be modelled. More in detail, the number of ambient bounces - $a b$ (that is to say the maximum number of bounces of the diffuse indirect component) have been set to two instead of four because the vast amount of glazed surfaces, as well as their orientation and the room size, make the diffuse component lower than the direct one. For the same reasons, the ambient resolution value -ar has been set to 128 (that expresses the maximum density of ambient values used for interpolation). These parameters, together with the use of ambient super-samples -as and ambient divisions - $a d$ values of 256 and 512, respectively, (that are mainly used for reducing noise effects when rendering), help keeping the simulation time reasonable without significantly affecting the simulation outcomes.

Table 3. Main Radiance parameters used for simulations.

\begin{tabular}{ccc}
\hline Parameter & Standard and Computer Classrooms & Gym \\
\hline -ab & 4 & 2 \\
-aa & 0.12 & 0.15 \\
-as & 400 & 256 \\
-ad & 2200 & 512 \\
-ar & 300 & 128 \\
\hline
\end{tabular}




\section{Results}

The outcomes of the simulations are presented first for the existing scenario, showing for each room peculiarities and issues in terms of the metrics that are described in Section 2.1. Based upon these results, specific design solutions for the different environments are proposed, and the metrics calculated again to show the improvements that is possible to achieve.

\subsection{Existing Scenario}

\subsubsection{Standard Classroom and Computer Classroom}

The standard and computer classrooms behave differently from the gym, but in a similar way to each other because of the same orientation and of the identical geometric layout and finishing materials. Only slight differences are recorded, imputable to the different furniture only, thus the results of both rooms are presented together for the sake of brevity.

As shown in Table 4, where the calculation of each metrics is reported for the existing configuration, in none of these spaces the statutory $a D F$ and $U R$ thresholds (amounting to $3 \%$ and $60 \%$, respectively) are satisfied. In fact, the $a D F$ values amount to $1.8 \%$ in the standard classroom and to $2.6 \%$ in the computer room, while the UR values are $37 \%$ and $24 \%$, respectively.

Table 4. Daylight metrics for the existing scenario.

\begin{tabular}{cccc}
\hline Metrics (\%) & Standard Classroom & Computer Classroom & Gym \\
\hline$a D F$ & 1.8 & 2.6 & 3.4 \\
$U R$ & 37 & 24 & 68 \\
$s D A$ & 90.4 & 96.5 & 97 \\
$A S E$ & 53.4 & 49 & 68.2 \\
$U D I<100$ lux & 4.8 & 0.3 & 0 \\
$U D I 100-2000$ lux & 72.5 & 76.3 & 93.6 \\
$U D I>2000$ lux & 22.7 & 23.4 & 6.4 \\
\hline
\end{tabular}

The $s D A$ metrics suggests a good daylight availability in both cases, with around $90 \%$ and $96 \%$ of the room area that is daylit with more than 300 lux for at least half of the occupancy time. ASE values of $53.4 \%$ and $49 \%$ are predicted in the standard classroom and computer room in order, which are significantly lower than the $68.2 \%$ value that was recorded in the case of the gym (see next subsection) because of the lower amount of glazed surfaces and of the different orientation, which excludes the direct sunlight contribution for most of the time.

In terms of UDI distribution, the percent of time when daylight levels fall within the useful range is pretty much the same for these rooms, being around $72 \%$ for the classroom against $76 \%$ for the computer room, while the percent of occupied time within the UDI $>2000$ lux bin is around $23 \%$ in both cases.

If looking at glare issues, the fisheye pictures that are reported in the Appendix A refer to the observers' point of view reported in the plans. The glare sources are highlighted as coloured patches, together with the instantaneous DGPS values achieved during a summer day (1 June at 10 a.m.) and a winter day (1 December at 10 a.m.). The observers' positions have been chosen by running the simulations under clear-sky conditions and identifying the points where the illuminance values were the highest at solstices and equinoxes. In the case of the standard and computer classrooms, very different instantaneous values of $D G P s$ both in wintertime ( 0.48 for the standard classroom against 0.16 for the computer classroom) and in summertime (0.62 against 0.19 , respectively) are predicted.

This different behavior is confirmed by the annual DGPS calculations for the same observers' position, as reported in Figure 4a,b through the "month-hour" diagrams, which was first introduced by Kambezidis et al. [26]. Here, the columns identify the month of the year, and the rows identify the hours of the day. The hourly DGPs values are reported using coloured patches: green patches stand for 
imperceptible glare $(D G P S<0.35)$, yellow patches for perceptible glare $(0.35 \leq D G P s<0.40)$, orange patches for disturbing glare $(0.40 \leq D G P s<0.45)$, and red patches for intolerable glare $(D G P S \geq 0.45)$.

(a)
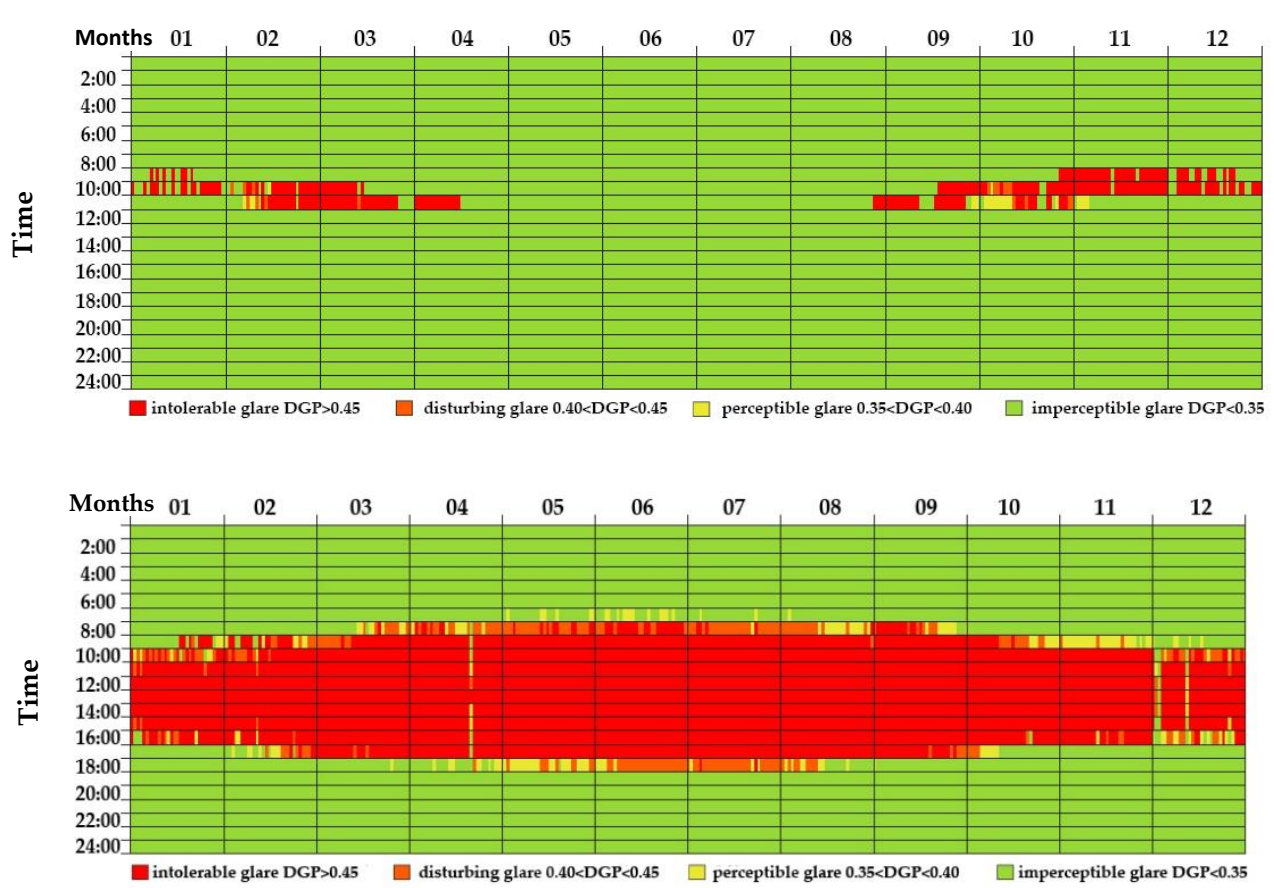

(c)

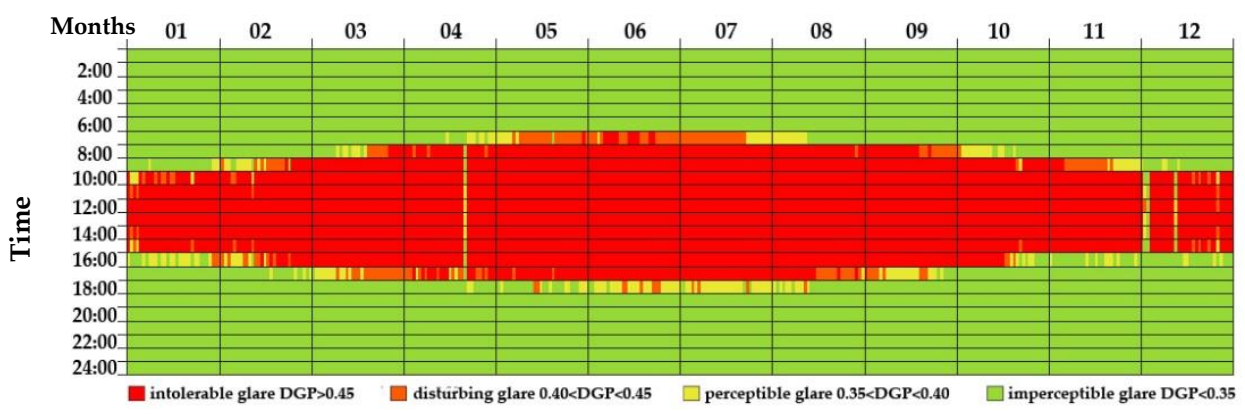

Figure 4. Annual Daylight Glare Probability (DGPs) calculation for the current configuration: (a) standard classroom; (b) computer classroom; and, (c) gym.

What emerges from these pictures is that intolerable glare is seldom predicted for the classroom, and this happens only for some hours during winter and transition seasons (January to April and September to December) from 10 a.m. to 11 a.m., when the sun's position is lower over the sky. On the other hand, intolerable glare is expected for the computer classroom for most of the occupancy time throughout the year, mainly because the selected observer is close to the window and it suffers from reflections of direct sunlight on the monitors.

\subsubsection{Gym}

The simulations run under the current room configuration show how only the gym comply with the prescriptions being set by the Italian building codes for schools in terms of achievement of the minimum $a D F$ and $U R$ values listed in Table 1 . In fact, if looking at Table $4, a D F$ amounts to $3.4 \%$ and $U R$ amounts to $68 \%$ respectively.

For the same room, the $s D A$ metrics delineates good daylight availability (the indoor illuminance is higher than 300 lux in $97 \%$ of the space for at least $50 \%$ of the occupancy period) because of the large amount of windows that are placed on the west and east oriented walls. For the same reasons, 
a high value of the ASE metrics (amounting to 68.2\%) should be expected because of direct sunlight entering the gym both in the morning from the east exposed windows and in the afternoon from the west exposed windows.

However, this piece of information is not enough to support the occurrence of glare issues. In fact, if looking at the UDI distribution in Table 4, it is seen that illuminance values are for almost $94 \%$ of the time within the 'useful' range of 100 to 2000 lux, with just a few hours of the year (around 6\%) being above the upper threshold. Furthermore, glare is a complex phenomenon to assess as it depends on several concurrent factors not yet fully understood $[16,17,27]$. From the fisheye pictures reported in the Appendix A, it appears that during the above-mentioned summer and winter days DGPS values as high as 0.24 should be expected, and thus an imperceptible glare condition is predicted for this observer's position irrespective of different sun's heights.

To have a long-term understanding of glare issues, a yearlong DGPs calculation has been carried out for the same observer's positions used for the instantaneous calculation. The corresponding results are presented in Figure $4 \mathrm{c}$ for the gym and shows that DGPs values are higher than 0.45 for most of the occupied hours (from 8 a.m. to 1 a.m.), thus highlighting the need for implementing some shading provision on the west and east oriented windows.

Furthermore, exemplary hourly luminance patterns during 7 December from 7 a.m. to 5:30 p.m. are reported in the supplementary materials section by using animated GIF pictures of the three rooms discussed so far. Although rather qualitative, this representation makes easy to identify the presence of direct sunlight patches falling within the observer's field of view at different times of the year, thus helping to inform the design of the various shading and re-directing devices discussed in the next subsection.

\subsection{Retrofit Scenario}

\subsubsection{Standard Classroom}

The analysis of the current daylight fruition in the standard classroom revealed, on the whole, good daylight availability, as pointed out by the $s D A$ and useful UDI metrics amounting to $90.4 \%$ and $72.5 \%$, respectively. On the other hand, daylight is unevenly distributed within the room $(U R=37 \%)$, with peak illuminance values being achieved close to the windows and rapidly declining if moving away from them. These issues are fairly typical for single-sided daylit spaces [28,29], and a range of design options can be implemented for reducing daylight levels close to the windows, while also improving those at the bottom of the room and thus increasing the overall uniformity. In particular, the refurbished scenario first aimed at reducing direct sunlight contribution by adding an external horizontal overhang at the top of the clerestory. Secondly, the bottom of the clerestory has been provided with a light shelf with internal and external protrusions, in order to bring daylight in and reflect it further inside through a highly reflective false ceiling.

Different geometrical solutions have been analyzed for the overhang and the light shelf (both internal and external sections) by varying their depth (more insights on this aspect can be found in parametric studies, such as ref. [30]), while in the case of the false ceiling, a planar and a double-curve configuration declining towards the bottom of the room have been investigated.

Various optical properties combinations for the glazing (namely the visible transmittance), the light shelf and the false ceiling (their diffuse and specular reflectance components in order) have been explored as well. The optimal combination resulted in:

- depth of the external overhang: $0.4 \mathrm{~m}$;

- $\quad$ width of the light shelf: $1 \mathrm{~m}$ externally $+0.8 \mathrm{~m}$ internally; and,

- double-curve false ceiling, with the lowest height set at $1 \mathrm{~m}$ from the ceiling, with 0.85 diffuse reflectance and 0.2 specular reflectance.

Reflective glazing (visible transmittance $=0.65$ ) has been used for the biggest panes below the clerestory (see Figure 5), while the light shelf exhibits a diffuse reflectance of 0.85 and a specular 
component of 0.5 . The use of light shelves and ceilings with a specular component, aimed to enhance the amount of light re-directed towards the bottom of the room, has been described by other researchers [31,32] and it is actually observed in real products that are available on the market. In particular, a specular behaviour has been found to improve illuminance levels and their uniformity in winter and in the mid-seasons, while diffuse lightshelves perform better at high solar altitudes (in summer) [28].

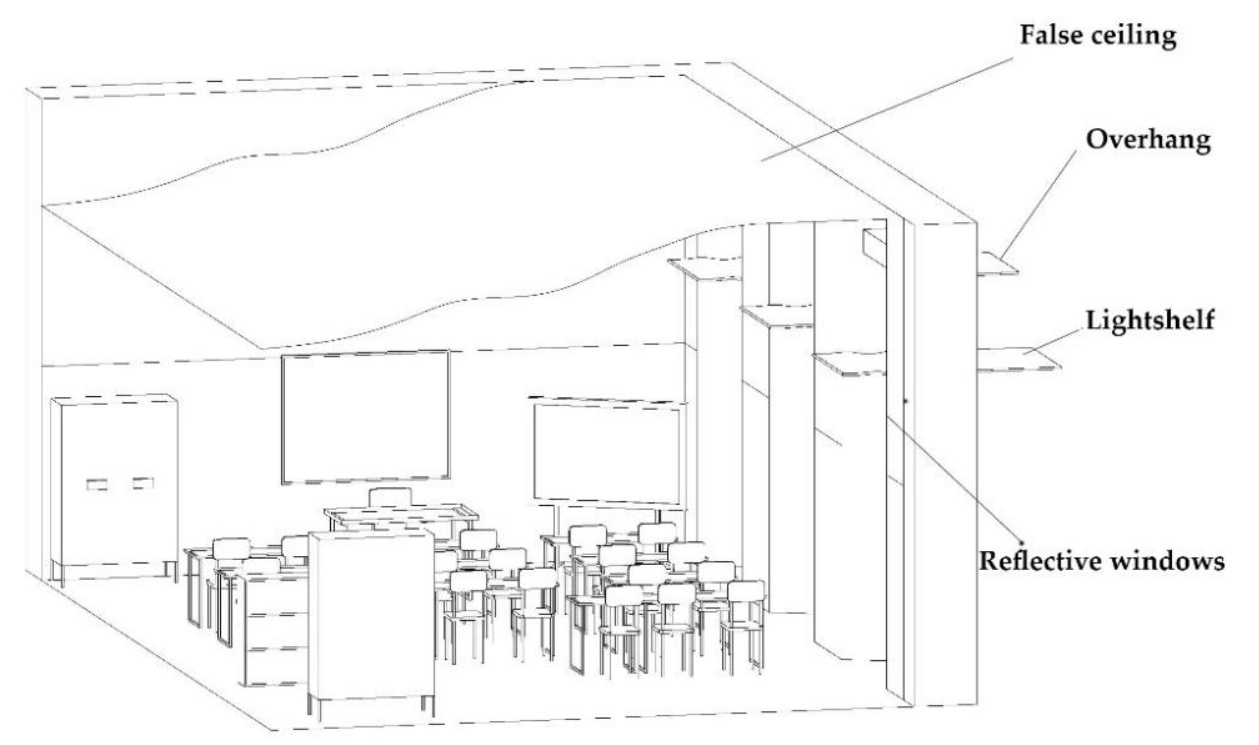

Figure 5. Design solutions for the standard south-oriented classroom.

The use of these design solutions allowed for improving all of the metrics except for the $a D F$, which dropped from $1.8 \%$ to $0.8 \%$, and for the $s D A$ that dropped from $90.4 \%$ to $74.1 \%$. These results sound reasonable, since the amount of light entering the room has been reduced by the combined action of the external overhang, the light shelf, and the reflective glazing. On the other hand, daylight is more evenly distributed thanks to the internal light shelf that re-directs the sunlight to the highly-reflective ceiling, which in turn conveys the light deep to the end of the room. This leads to a reduction in the UDI over 2000 lux metrics from the original value of $22.7 \%$ to the new one of $3.4 \%$, and to an increase of the useful UDI (i.e., that in the range of 100 to 2000 lux) from $72.5 \%$ to $89.2 \%$, respectively.

These improvements can be appreciated if looking at Table 5, where all of the values are summarized for both the existing and refurbished scenario, and where a column named 'effect' identifies if a metrics improves (better) or worsens (worse) the corresponding daylight performance if compared to its original value. In terms of annual DGP values, Figure 6 shows only minor improvements, meaning that glare is not an issue for the chosen observer's position.

Table 5. Daylight metrics for the standard classroom: existing and refurbished scenario.

\begin{tabular}{cccc}
\hline Metrics (\%) & Existing Scenario & Refurbished Scenario & Effect \\
\hline$a D F$ & 1.8 & 0.8 & Worse \\
$U R$ & 37 & 55 & Better \\
$s D A$ & 90.4 & 74.1 & Worse \\
$A S E$ & 53.4 & 6.3 & Better \\
$U D I<100$ lux & 4.8 & 7.4 & Better \\
$U D I 100-2000$ lux & 72.5 & 89.2 & Better \\
$U D I>2000$ lux & 22.7 & 3.4 & Better \\
\hline
\end{tabular}




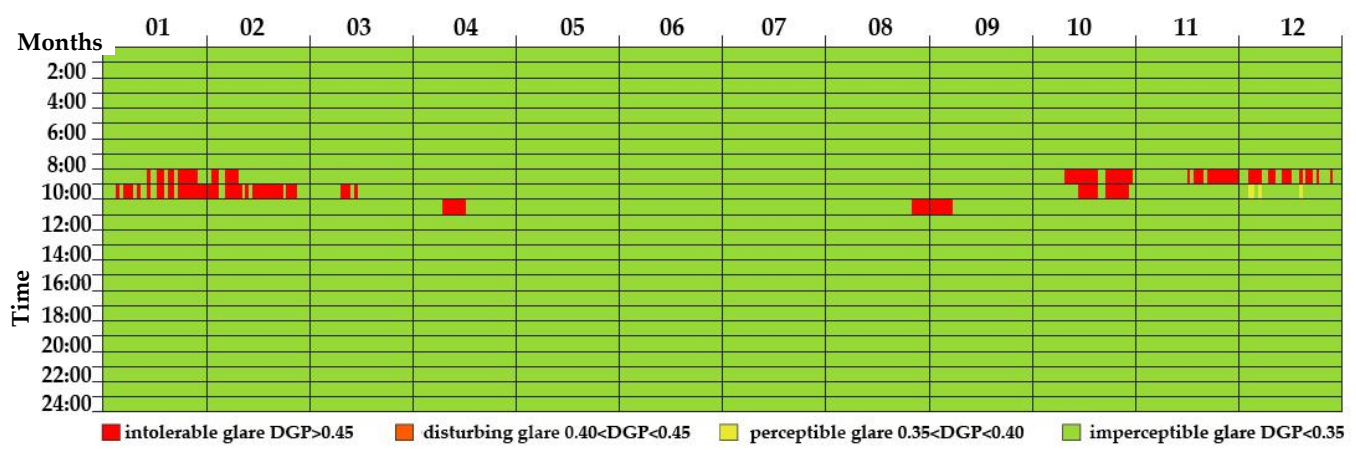

Figure 6. Annual DGPS calculation for the standard classroom. Refurbished scenario.

\subsubsection{Computer Classroom}

As discussed in Section 3.1, the computer classroom differs from the standard classroom only in terms of the furnishing layout, so theoretically it would be possible to apply the same measures that are discussed above. However, the discontinuous use of this room suggests to implement different and more flexible solutions, with lower impact on room geometry and possibly on construction costs as well.

Accordingly, the focus was on reducing the high illuminance values in proximity of the windows, where approximately one-third of the desks are accommodated. To this aim, the benefits of using reflective glazing with visible transmittance as high as 0.5 and internal blinds (curtains) with diffuse reflectance equal to 0.45 have been analysed as two different options (see Figure 7).

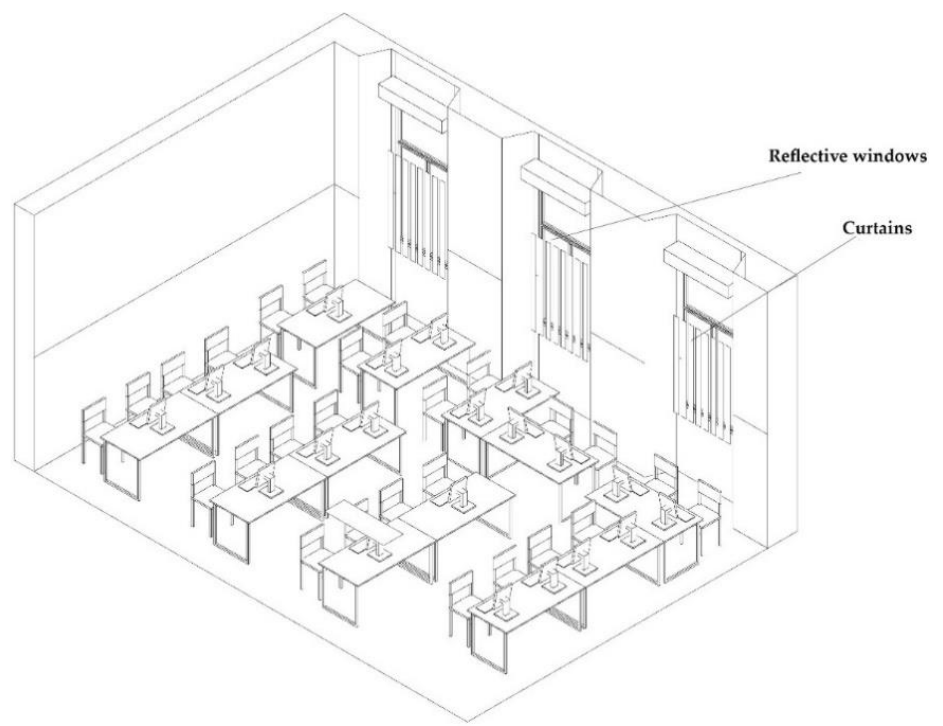

Figure 7. Design solutions for the computer room.

Both of the alternatives behave rather similarly, but a preference is given to the installation of curtains because of the costs and the higher flexibility of use over reflective windows.

By comparing the metrics for the existing and the refurbished cases (Table 6), it can be observed that the main contribution of the curtains is the reduction of the amount of light entering the room, as demonstrated by the lower $s D A(81.6 \%$ against $96.5 \%)$ and $U D I$ exceeded values $(3.6 \%$ against $23.4 \%$ ). Nonetheless, the reduced incoming light brings some benefits in terms of useful UDI, since now the average illuminance value is expected to be in the range of 100 lux to 2000 lux for $96.1 \%$ of the time against the original $76.3 \%$ value. The UR also improves, increasing from $24 \%$ to $33 \%$, but it still keeps below the threshold of $60 \%$ prescribed by the Italian regulations. 
Table 6. Daylight metrics for the computer classroom: existing and refurbished scenario.

\begin{tabular}{cccc}
\hline Metrics (\%) & Existing Scenario & Refurbished Scenario & Effect \\
\hline$a D F$ & 2.6 & 2.4 & Slightly worse \\
$U R$ & 24 & 33 & Better \\
$s D A$ & 96.5 & 81.6 & Worse \\
$A S E$ & 49 & 49 & $=$ \\
$U D I<100$ lux & 0.3 & 0.3 & $=$ \\
$U D I 100-2000$ lux & 76.3 & 96.1 & Better \\
$U D I>2000$ lux & 23.4 & 3.6 & Better \\
\hline
\end{tabular}

Negligible differences are expected in terms of $a D F$ (2.4\% of the refurbished case against $2.6 \%$ of the base case), while it is worth noticing how the ASE value keeps constant at $49 \%$, just because this is calculated without accounting for the operation of movable shading devices, according to the IES definition [4].

Finally, the annual DGPS calculation reported in Figure 8 shows no glare occurrence at every time of the year. This happens because curtains are supposed to be used whenever the DGPs calculation for the observer's viewpoint is expected to be above 0.40 ; different activation strategies would likely perform differently, but they have not been further explored because of the discontinuous use of this room.

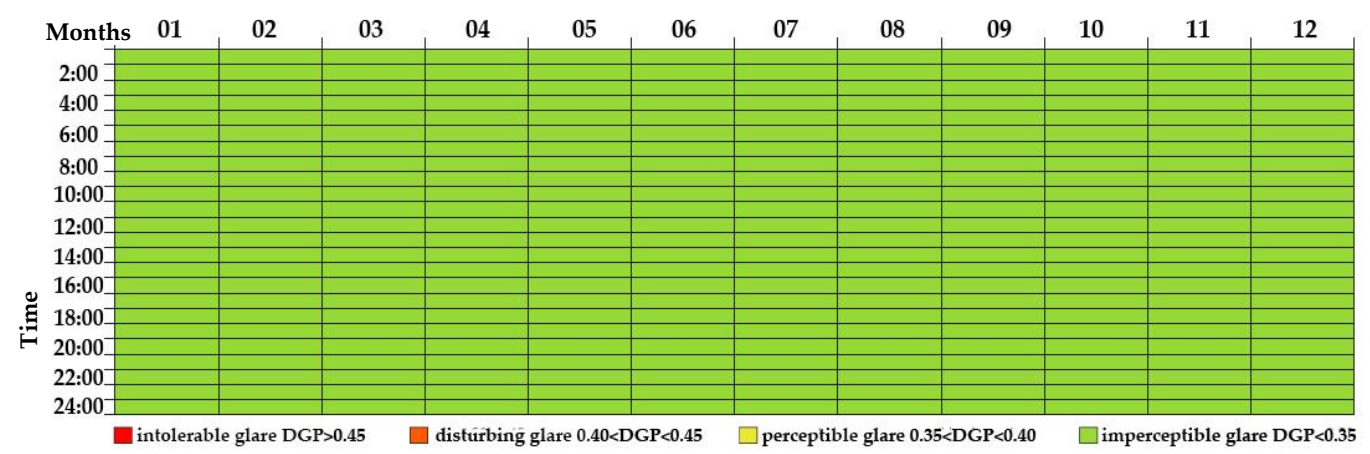

Figure 8. Annual DGPS calculation for the computer classroom. Refurbished scenario.

\subsubsection{Gym}

In the case of the gym, the main issue to be tackled is the rather high illuminance values due to direct sunlight only, as expressed by an $A S E=68.2 \%$. When considering that this room presents large glazed surfaces exposed both due to east and west, which are hit from direct sunlight during the morning and the afternoon, respectively, when the sun height is low on the horizontal, the proposed intervention aimed at excluding this contribution by applying louvers on both sides.

The optimal configuration, achieved by running several simulations, was found when using aluminium blades of $0.25 \mathrm{~m}$ width, separated from each other by $0.25 \mathrm{~m}$, and showing a diffuse reflectance that is equal to 0.5 and a specular component equal to 0.2 .

Moreover, a double-curved false ceiling is proposed, hanging down by approximately $1 \mathrm{~m}$ from the centreline of the roof and showing the same optical properties as the false ceiling being applied to the standard classroom ( 0.85 diffuse reflectance and 0.2 specular reflectance). This is expected to raise the UR from the original $68 \%$ value (see Figure 9 for an axonometric representation of the proposed interventions).

Simulation results show that, despite that the gym is almost entirely lit with more than 300 lux for at least $50 \%$ of its occupancy time ( $s D A=99.2 \%$ ), the ASE value is now as low as $12.1 \%$ and the time during which illuminance is higher than 2000 lux is only $5.7 \%$ of the occupancy period against the original $6.4 \%$ value. Moreover, even if the $a D F$ drops down from $3.4 \%$ to $1.8 \%$, the useful UDI metrics 
has slightly improved (from $93.6 \%$ to $94.3 \%$ ), meaning that indoor lighting conditions are improved rather than worsened (Table 7).

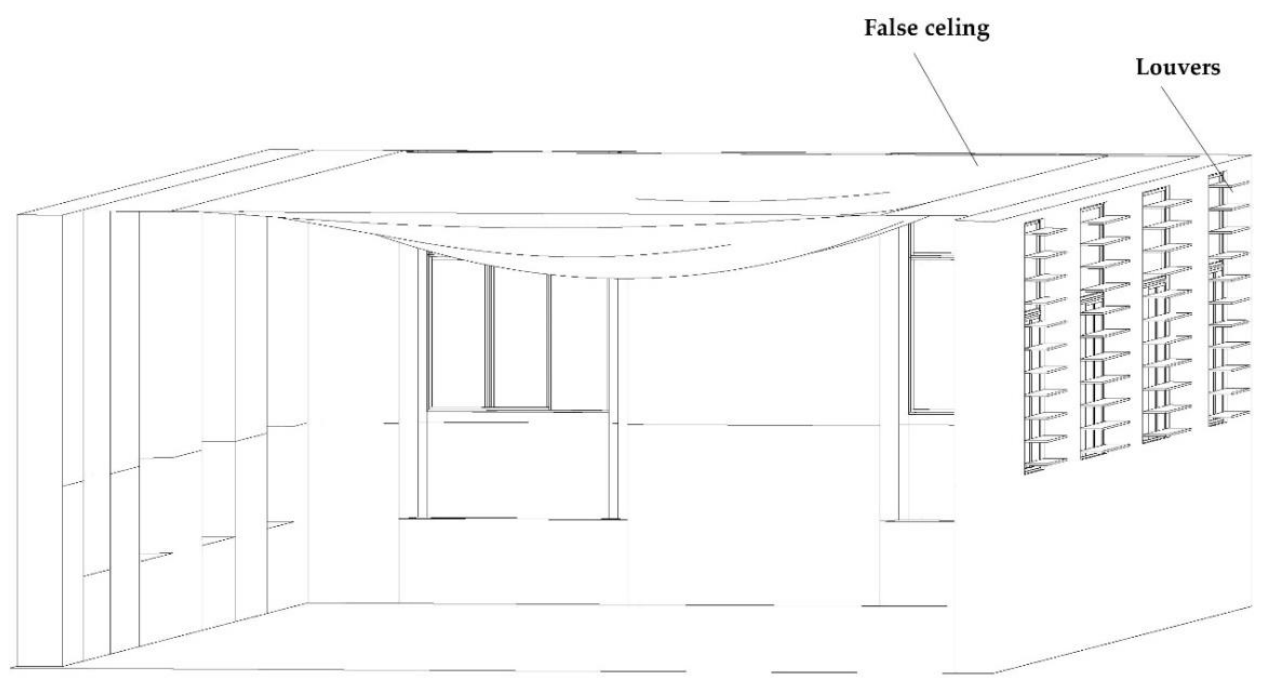

Figure 9. Design solutions for the gym.

Table 7. Daylight metrics for the gym: existing and refurbished scenario.

\begin{tabular}{cccc}
\hline Metrics (\%) & Existing Scenario & Refurbished Scenario & Effect \\
\hline$a D F$ & 3.4 & 1.8 & Worse \\
$U R$ & 68 & 91 & Better \\
$s D A$ & 97 & 99.2 & Slightly better \\
$A S E$ & 68.2 & 12.1 & Better \\
$U D I<100$ lux & 0 & 0 & $=$ \\
$U D I 100-2000$ lux & 93.6 & 94.3 & Slightly better \\
$U D I>2000$ lux & 6.4 & 5.7 & Slightly better \\
\hline
\end{tabular}

Finally, the annual DGPS calculation reported in Figure 10 for the observer's position depicted in the Appendix A clearly indicates that with the proposed interventions intolerable glare is expected only for very few hours in a year (around 11AM in February and September and around 5PM in April and September). In the remaining of the year, glare conditions are tagged as imperceptible (i.e., with $D G P s<0.35)$; this represents a strong improvement if compared with the annual DGPs calculation of the existing case reported in Figure 4c.

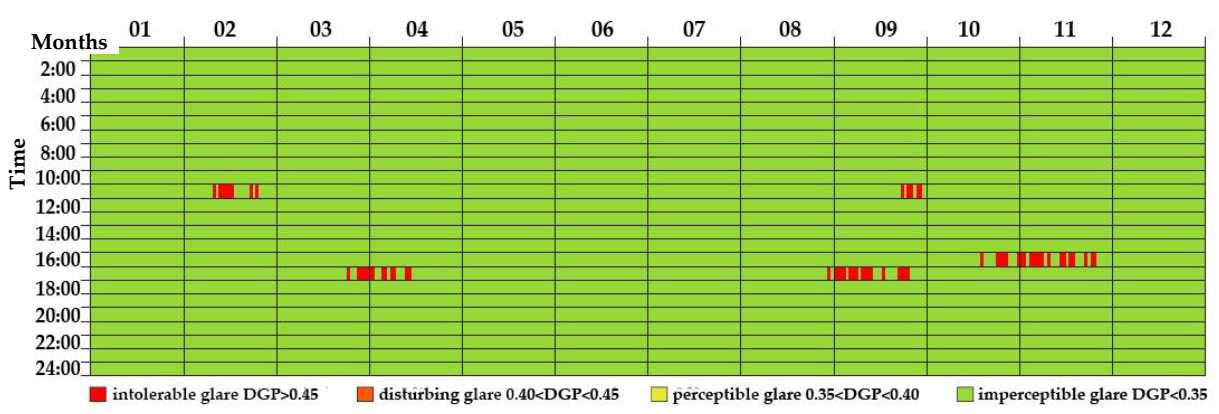

Figure 10. Annual DGPs calculation for the gym. Refurbished scenario.

\section{Discussion}

The outcomes of the daylight simulations presented in the previous section helped inform the design of a retrofit intervention for a school building that is located in the sunny climate of Sicily (Italy). 
Three rooms with different orientation, shape, function, and furniture arrangement have been considered for designing the most suitable shading and re-directing devices.

What clearly emerges from the analysis of the different metrics is that, if following the current practice of simply complying with the statutory $a D F$ and $U R$ values, these devices would likely not be installed. In fact, both the standard and computer classrooms show an $a D F$ that is lower than $3 \%$, suggesting that more daylight would be desirable, e.g., by installing larger windows. However, the use of the $s D A$ and $A S E$ metrics suggests that there is already a good daylight availability throughout the year, and, on the other hand, direct sunlight may cause glare issues.

Further analyses that were conducted with the help of the UDI metrics allow for binning of the illuminance values achieved on the work plane (i.e., the ideal surface assumed to host the main visual task) under different sky conditions, pointing out that for more than $20 \%$ of the occupancy time illuminance seems to be excessive, especially close to the windows. This information is supported by glare calculations that are carried out in terms of instantaneous and yearlong DGPS values for observers that are placed in proximity of the windows.

Given the different orientation and amount of glazed surfaces already available, the gym appears the only room complying with the statutory requirements in terms of $a D F$ (above 3\%) and UR values (above 60\%). Nonetheless, the high value that is achieved by the ASE metrics (almost 70\%) suggests considering the implementation of some shading device in order to reduce or completely cut out direct sunlight contribution.

These results consolidate the existing knowledge about the use of CBDM simulations for informing the design process of school buildings [33,34], and further the understanding of dynamic daylight metrics by using a wide range of illuminance- and luminance-based metrics in a comprehensive way. The comparison with the results of traditional and commonly adopted static metrics shows that the messages coming from these static metrics can be deceiving. It is thus reaffirmed that static metrics are not solid enough to support the appraisal of daylight exploitation, at least under mostly sunny and clear sky conditions. Further, it is not possible to use just one metrics (static or dynamic) to judge if and for how long a space is 'well' daylit, but rather different metrics are needed to consider both the spatial and temporal variability of daylight.

What still appears to be critical is the assessment of glare, which depends on several human-related and room-related factors, and how well-established metrics, such as the DGPs, could inform the design process. In fact, the calculation of this metrics is strongly dependent on the field of view, so there could be observers suffering from glare for most of the time while others would not. Moreover, as reported by Berardi and Wang in a paper dealing with daylight conditions in an atrium house [35], inconsistencies in the prediction of glare - and of its intensity - should be expected if comparing different glare indexes. When also considering the long simulation times that are required to carry out year DGPs calculations (up to four hours for the standard classroom using an i7 2670QM processor), a criterion to carefully select the worst observer's position before running these simulations would be needed.

\section{Conclusions}

The introduction of the Climate Based Daylight Modelling (CBDM) concept has questioned the robustness of the traditional practice of relying on static (i.e., fixed) sky conditions to appraise daylight levels within buildings. This paper advanced the knowledge about the use of recently developed CBDM metrics by proposing a detailed daylight analysis of a school building located in Agira (Italy), a town that experiences sunny and clear-sky conditions for most of the year.

Hourly simulations, run using the Radiance-based DIVA software for a calibrated daylight model, allowed to identify the main issues of rooms presenting different orientation, shape, function, and furniture, and helped to inform the design of the required shading and re-directing devices.

More in detail, the calculation of the spatial Daylight Autonomy $(s D A)$ metrics revealed good daylight availability for all of the rooms analysed (with values always higher than $90 \%$ ), but on the other hand the Annual Sunlight Exposure (ASE) calculation evidenced a risk of glare occurrence 
especially for the gym $(A S E=68.2 \%)$. This happens because of the large glazed surfaces that are oriented due to both west and east, since they expose the room to direct sunlight in the morning (from east) and in the afternoon (from west). Glare risks have been confirmed by the calculation of the simplified Daylight Glare Probability (DGPs) metrics for some observers' position and by the number of hours when the Useful Daylight Illuminance (UDI) metric is above the upper threshold of 2000 lux (which happens for around 23\% of the occupied hours in the standard and computer classrooms).

Based on these outcomes, retrofit solutions that are aimed at reducing and re-directing direct sunlight, such as external overhangs, light shelves, louvers, and reflective ceilings, have been designed and their efficacy tested by calculating all of the static and dynamic metrics again. The results showed that, despite a reduction in daylight levels in proximity of the windows, as shown by lower $s D A$ values than in the base case, higher illuminance values were expected at the bottom of the rooms.

In this way, the useful UDI metrics keeps above $90 \%$ in all rooms, the ASE metrics is close to the threshold of acceptability of $10 \%$ (except for the computer classroom) and the UR significantly improves in all rooms.

However, it must be pointed out that a design that was carried out using CBDM metrics appears in contrast with what would be suggested if considering the average Daylight Factor $(a D F)$ metrics alone, as it is usually done in common design practice. In fact, all of the proposed design solutions lower the $a D F$ values if compared to the existing scenario, which are already below the minimum threshold, as prescribed by the Italian regulations for classrooms. This would likely suggest a designer to bring in more daylight by increasing the glazed surfaces; however, such a choice would actually be wrong in relation to the sunny hours, which are much more frequent than cloudy hours in Southern Italy.

These outcomes rebate the need of performing more accurate and dynamic daylight simulations using recorded (i.e., varying) rather than fixed sky conditions to correctly inform the design process.

Supplementary Materials: The following are available online at http:/ /www.mdpi.com/2071-1050/10/8/2653/s1, Figure S1: Hourly luminance distribution for a typical user of the standard classroom, computer classroom and gym, respectively, during 7 December from 7 a.m. to 5:30 p.m.

Author Contributions: Conceptualization, Methodology and Writing, V.C.; Writing-review and editing and Data Curation, G.E.; Supervision and Resources, L.M.; Investigation and Visualization, F.P.N.

Acknowledgments: The authors would like to warmly thank all the teachers and pupils of the 'Guglielmo Marconi' elementary school in Agira (Italy) for their kind support throughout the measurement campaign.

Conflicts of Interest: The authors declare no conflict of interest.

\section{Appendix}

This appendix reports the instantaneous DGPs values achieved by the observers' positions depicted on the left column for every room analyzed during a typical summer day (1of June at 10 a.m., middle column) and winter day (1 December at 10 a.m., right column) respectively.

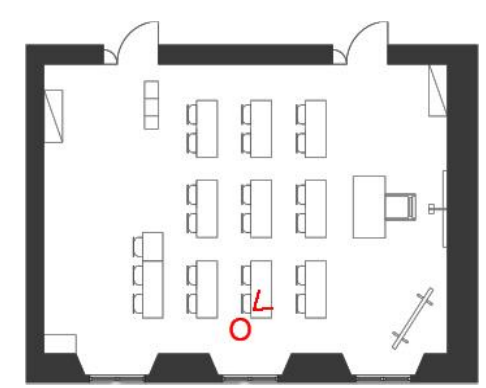

STANDARD CLASSROOM

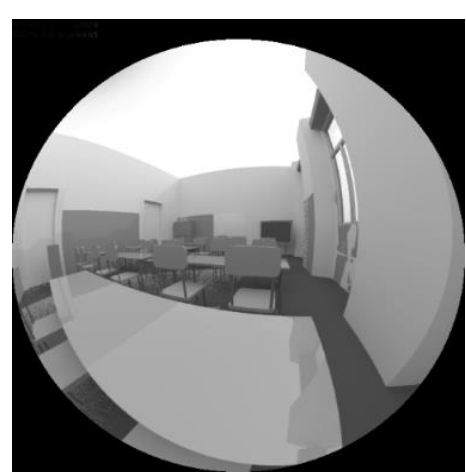

DGPS $=0.48$

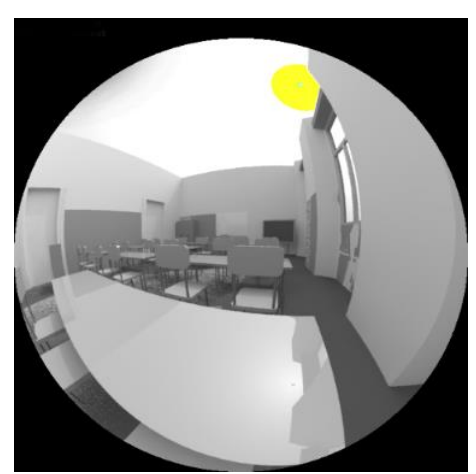

$D G P S=0.62$ 

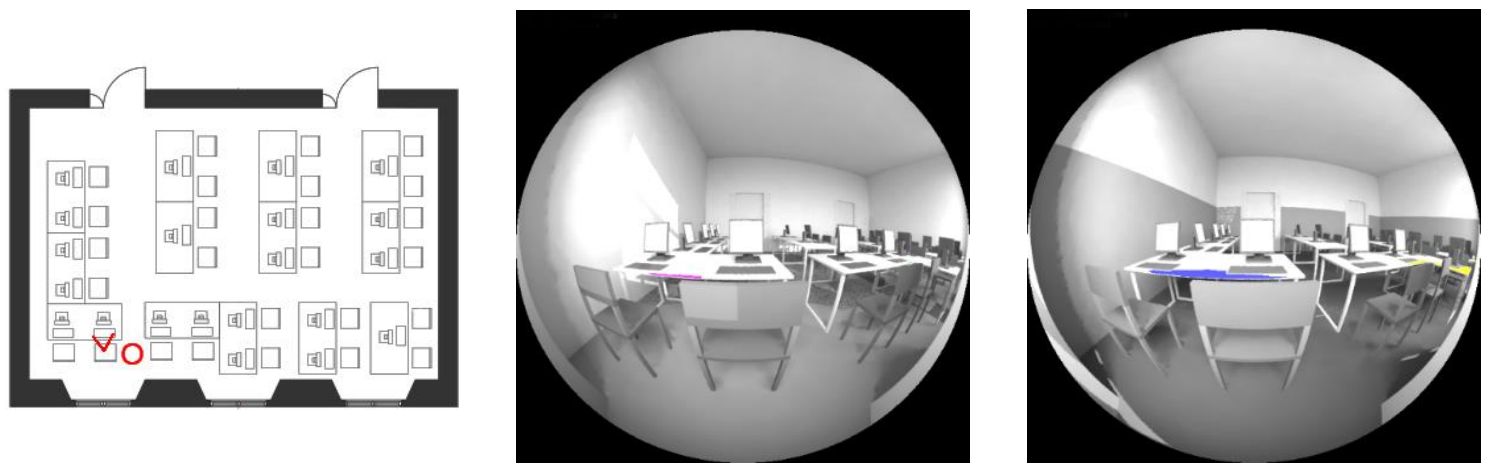

COMPUTER CLASSROOM

$D G P S=0.16$

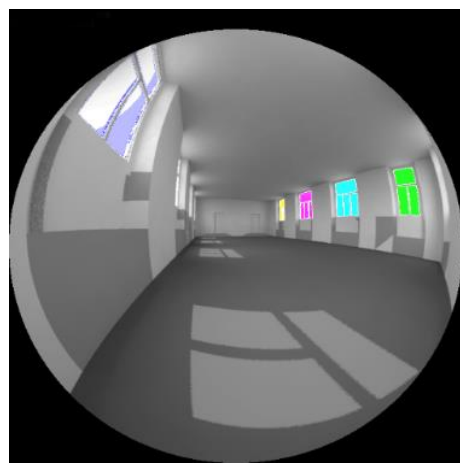

$D G P S=0.24$
$D G P S=0.19$

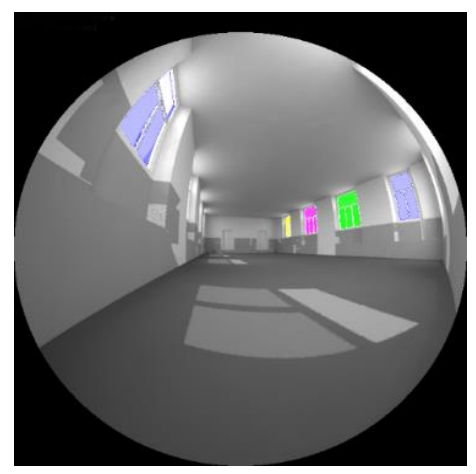

$D G P S=0.21$

\section{References and Notes}

1. Mardaljevic, J. Simulation of annual daylighting profiles for internal illuminance. Light. Res. Technol. 2000, 32, 111-118. [CrossRef]

2. Reinhart, C.F.; Herkel, S. The Simulation of annual daylight illuminance distributions-A state-of-the-art comparison of six RADIANCE-based methods. Energy Build. 2000, 32, 167-187. [CrossRef]

3. Crisp, V.H.C.; Littlefair, P.J. Average laborious procedure prediction. In Proceedings of the National Lighting Conference (CIBSE), London, UK; 1984.

4. Illuminating Engineering Society. Approved Method: IES Spatial Daylight Autonomy (sDA) and Annual Sunlight Exposure (ASE); IES: New York, NY, USA, 2012.

5. Nabil, A.; Mardaljevic, J. Useful daylight illuminances: A replacement for daylight factors. Energy Build. 2006, 38, 905-913. [CrossRef]

6. Education and Skills Funding Agency. Priority School Building Programme (PSBP). Available online: https:/ / www.gov.uk/government/collections/priority-school-building-programme-psbp (accessed on 26 June 2018).

7. Bellia, L.; Pedace, A.; Fragliasso, F. The role of weather data files in Climate-based Daylight Modeling. Sol. Energy 2015, 112, 169-182. [CrossRef]

8. Reinhart, C.F.; Mardaljevic, J.; Rogers, Z. Dynamic daylight performance metrics for sustainable building design. LEUKOS—J. Illum. Eng. Soc. North Am. 2006, 3, 7-31.

9. Costanzo, V.; Evola, G.; Marletta, L. A Review of Daylighting Strategies in Schools: State of the Art and Expected Future Trends. Buildings 2017, 7, 41. [CrossRef]

10. Littlefair, P. Opinion: Climate-based daylighting modelling in practice. Light. Res. Technol. 2015, 47, 512. [CrossRef]

11. Tregenza, P. Opinion: Climate-based daylight modelling or daylight factor? Light. Res. Technol. 2014, 46, 618. [CrossRef] 
12. Mardaljevic, J. Climate-Based Daylight Modelling And Its Discontents. In Proceedings of the CIBSE Technical Symposium, London, UK, 16-17 April 2015; pp. 1-12.

13. Wu, W.; Ng, E. A review of the development of daylighting in schools. Light. Res. Technol. 2003, 35, 111-125. [CrossRef]

14. Lindelöf, D.; Morel, N. Bayesian estimation of visual discomfort. Build. Res. Inf. 2008, 36, 83-96. [CrossRef]

15. Carlucci, S.; Causone, F.; De Rosa, F.; Pagliano, L. A review of indices for assessing visual comfort with a view to their use in optimization processes to support building integrated design. Renew. Sustain. Energy Rev. 2015, 47, 1016-1033. [CrossRef]

16. Pierson, C.; Wienold, J.; Bodart, M. Review of Factors Influencing Discomfort Glare Perception from Daylight. LEUKOS-J. Illum. Eng. Soc. North Am. 2018, 14, 111-148. [CrossRef]

17. Wienold, J.; Christoffersen, J. Evaluation methods and development of a new glare prediction model for daylight environments with the use of CCD cameras. Energy Build. 2006, 38, 743-757. [CrossRef]

18. Wienold, J. Dynamic daylight glare evaluation. In Proceedings of the IBPSA 2009 Conference, Glasgow, Scotland, 27-30 July 2009; pp. 944-951.

19. Wienold, J. Dynamic simulation of blind control strategies for visual comfort and energy balance analysis. In Proceedings of the IBPSA 2007 Conference, Beijing, China, 3-6 September 2007; pp. 1197-1204.

20. Luce e illuminazione-Illuminazione dei posti di lavoro-Parte 1: Posti di lavoro in interni. UNI EN 12461-1:2011, 2011. (In Italian)

21. Luce e illuminazione-Locali scolastici-Criteri generali per l'illuminazione artificale e naturale. UNI 10840:2007, 2007. (In Italian)

22. Reinhart, C.; Rakha, T.; Weissman, D. Predicting the Daylit Area-A Comparison of Students Assessments and Simulations at Eleven Schools of Architecture. Leukos 2014, 10, 193-206. [CrossRef]

23. Ward, G.J.; Rubinstein, F.M. A new technique for computer simulation of illuminated spaces. J. Illum. Eng. Soc. 1988, 17, 80-91. [CrossRef]

24. Ward, G.L.; Shakespeare, R. Rendering with Radiance: The Art and Science of Lighting Visualization; Booksurge Llc: Charleston, SC, USA, 2007; ISBN 0-9745381-0-8.

25. Wilcox, S.; Marion, W. Users Manual for TMY3 Data Sets; Technical Report; National Renewable Energy Laboratory: Lakewood, CO, USA, May 2008.

26. Kambezidis, H.D.; Muneer, T.; Tzortzis, M.; Arvanitaki, S. Global and diffuse horizontal solar illuminance: Month-hour distribution for Athens, Greece in 1992. Light. Res. Technol. 1998, 30, 69-74. [CrossRef]

27. Cantin, F.; Dubois, M.C. Daylighting metrics based on illuminance, distribution, glare and directivity. Light. Res. Technol. 2011, 43, 291-307. [CrossRef]

28. Pellegrino, A.; Cammarano, S.; Savio, V. Daylighting for Green schools: A resource for indoor quality and energy efficiency in educational environments. Energy Procedia 2015, 78, 3162-3167. [CrossRef]

29. Korsavi, S.S.; Zomorodian, Z.S.; Tahsildoost, M. Visual comfort assessment of daylit and sunlit areas: A longitudinal field survey in classrooms in Kashan, Iran. Energy Build. 2016, 128, 305-318. [CrossRef]

30. Berardi, U.; Anaraki, H.K. The benefits of light shelves over the daylight illuminance in office buildings in Toronto. Indoor Built Environ. 2018, 27, 244-262. [CrossRef]

31. Meresi, A. Evaluating daylight performance of light shelves combined with external blinds in south-facing classrooms in Athens, Greece. Energy Build. 2016, 116, 190-205. [CrossRef]

32. Ho, M.C.; Chiang, C.M.; Chou, P.C.; Chang, K.F.; Lee, C.Y. Optimal sun-shading design for enhanced daylight illumination of subtropical classrooms. Energy Build. 2008, 40, 1844-1855. [CrossRef]

33. Zomorodian, Z.S.; Korsavi, S.S.; Tahsildoost, M. The effect of window configuration on daylight performance in classrooms: A field and simulation study. Int. J. Archit. Eng. Urban Plan 2016, 26, 15-24.

34. Zomorodian, Z.S.; Tahsildoost, M. Assessment of window performance in classrooms by long term spatial comfort metrics. Energy Build. 2017, 134, 80-93. [CrossRef]

35. Berardi, U.; Wang, T. Daylighting in an atrium-type high performance house. Build. Environ. 2014, 76, 92-104. [CrossRef]

(C) 2018 by the authors. Licensee MDPI, Basel, Switzerland. This article is an open access article distributed under the terms and conditions of the Creative Commons Attribution (CC BY) license (http:/ / creativecommons.org/licenses/by/4.0/). 